\title{
The role of personality traits in the choice and use of the compensation category of English language learning strategies
}

\author{
Seyed Hossein Fazeli \\ Abadan Branch, Islamic Azad University, Abadan, Iran \\ fazeli78@yahoo.com
}

\begin{abstract}
The present study aims to find out the role of personality traits in the prediction choice and use of the Compensatory English Language Learning Strategies (CELLSs) for learners of English as a foreign language. Four instruments were used, which were Adapted Inventory for Compensatory English Language Learning Strategies based on Compensation category of Strategy Inventory for Language Learning (SILL) of Rebecca L. Oxfords (1990), A Background Questionnaire, NEO-Five Factors Inventory (NEO-FFI), and Test of English as a Foreign Language (TOEFL). Two hundred and thirteen Iranian female university level learners of English language as a university major in Iran, volunteered to participate in this study. The intact classes were chosen. The results show that however, there is a significant relationship between each of three traits of personality and the choice and use of the cells, but personality traits cannot be a strong predictor to predict the choice and use of the CELLSs.
\end{abstract}

Keywords: Compensation category of language learning strategies, English learning, Personality traits.

\section{Introduction}

Since individual differences have been identified as variables influencing language learning outcome (Skehan, 1989; Larsen-Freeman \& Long, 1991); and as it was shown by the study of Marttinen (2008), the high percent of source of learners' knowledge comes from teacher; Horwitz (1988) encourages teachers to discover the prescriptive belief of their own students. Moreover, in order to provide successful instruction, teachers need to learn to identify their students' individual difference, and even they need to become more aware of how their teaching styles are appropriate to their learners' strategies (Oxford \& Cohen, 1992).

Recently some studies tend to concentrate more on individual differences in strategy performance (Toyoda, 1998; Oxford, 1992, 1993;). In such related studies, it was shown for strategy instruction to be affected; it should take all the variables into account (Oxford \& Crookball, 1989).

Since 1990s, there has been growing interest on how personality correlates to the academic performance. Personality has been conceptualized at different levels of breadth (McAdams, 1992), and each of these levels include our understanding of individual understanding. Moreover, individuals are characterized by a unique pattern of traits, and some study shows successful language learners choose strategies suit to their personalities (Oxford \& Nyikos, 1989). In addition, since LLSs are not innate but learnable (Oxford, 1994), broad justifications have been offered for the evaluation of personality traits as a predictor of the Compensatory English Language Learning Strategies (CELLSs).

In such way, the premise underlying line of this research is that success in CELLSs plays an important role in affecting learners' English language learning process.

\section{Review of literature}

The study of individual and personality differences is a central theme in psychology as well as the other areas of social and behavior sciences (Saklofske \& Eysneck, 1998).

The examination of variation in human behavior is referred to as the study of individual differences (Ehrman \& Dornyei, 1998). Such study of individual differences includes many subsets of studies such as the study of personality differences (Hampson \& Colman, 1995), and personality factors that are important in development of linguistic abilities (Ellis, 1985). Psychologically, it is a truism that people are different in many fundamental ways, and learners are individuals, and there are infinitive variables (Skehan, 1989). In this manner, Horwitz (1999) points out "language learners are individuals approaching language learning in their own unique way (p.558). In addition, individuals who are characterized as a particular psychological type, adopt different learning strategies (Brown, 2001). In such situation, the teachers must make the students aware of the range of the strategies they can adopt (Cook, 2008); and they must aware of the relationship between personality and academic performance (Eysenck, 1967; Cattel \& Butcher, 1968).

Foregoing has highlighted the main goal of the current study to document how personality traits related to the CELLSs. In such situation, there are some possible ways looking at the CELLSs and their relationship with personality traits. The first one is to see the choice and use of the CELLSs as an outcome of personality traits. The second one is to see them as having uni-directional causal role increasing personality traits. The third one is to see the relationship between the two as mutual, and causality is bi-directional.

\section{Methodology}

Participants

The chosen participants for this study were 213 female students studying at third grade (year) of English 
major of $\mathrm{B}$. A. degree, ranging age from 19 to 28 (Mean= 23.4, $S D=2$ ), in three branches of Islamic Azad University, which are named Abadan, Dezful, and Masjed-solyman in south of Iran.

The socio-economic status of participants, such as the participants' social background, and parents' level education was controlled as well by a questionnaire. Based on some indicators such as the parents' socioeducational background and occupation, the participants were matched as closely as possible for socio-economic background to minimize the effect of social class. Accordingly, the participants were classified as a middle class.

Because of the nature of this work (regarding the use of the CELLSs), a general English proficiency test for determining the proficiency level of participants in English was applied in order to minimize the effect of English language proficiency. As Jafarpour (2001) defines "the percent classification of subjects by the experimental test that corresponds to those by the criterion" (pp.32-33) (as cited in Golkar \& Yamini, 2007), top of subjects are 27\% and bottom of subjects are 27\% (Golkar \& Yamini, 2007), the participant whom were classified as intermediate subjects, were asked to participate in the current study.

\section{Instrumentation in the current study}

Four instruments were used to gather data in the current study.

Adapted Inventory for Compensation Category of English Language Learning Strategies: The Strategy Inventory for Language Learning (SILL) of Rebecca L. Oxford (1990) is a kind of self-report questionnaire that has been used extensively by researchers in many countries, and its reliability has been checked in multiple ways, and has been reported as high validity, reliability and utility (Oxford, 1996). In addition, factor analysis of the SILL is confirmed by many studies (Oxford \& Burry-Stock, 1995; Oxford, 1996; Hsiao \& Oxford, 2002). In this way, as Ellis (1994) believes the Oxford's taxonomy is possibly the most comprehensive one that is available currently. Several empirical studies have been found moderate intercorrelation between the items of six categories in the SILL (Oxford \& Ehrman, 1995).

Based on the Compensation category of the SILL, the investigator adapted a questionnaire. In adaptation of each instrument from one language to another in research works, some problems occur, such as the problem of translation one questionnaire to another language (Perera \& Eysenck, 1984). As same as the other two questioners (NEO-FFI and Background Questionnaire), adapted CELLSs inventory was checked through back translation into English by three English teachers and three psychologists who were fully proficient in both languages (English and Persian), in order to check the consistency with English version, and based on the pilot study was performed. The items were corrected until full agreement among the translators was achieved, and the pilot study confirmed such translated items. In addition, the balance between spoken and written Persian was checked.

In the case of such questionnaire, three psychologists and three English teachers were asked to check the questionnaire from two points of view. Firstly, since both psychologists and English teachers were fully proficient in both languages (English and Persian), they were asked to check the translated version of the questionnaire in order to check the consistency with English version of them. Secondly, since both the psychologists and English teachers were professional in related study of the questionnaire, they were asked to check the psychometrics of the questionnaire.

After full agreement among the psychologists and English teachers was achieved, and the pilot study confirmed the items of such questionnaire, it was administrated in the main study.

Test of English as a Foreign Language (TOEFL)

\section{$A$ background questionnaire}

NEO-Five Factors Inventory (NEO-FFI)

The Big Five Personality Questionnaire is based on the Big Five Factor Model of personality whose major proponents are Lewis Goldberg, Paul Costa, and Robert McCare. This theory proposes that five broad dimensions provide complete description of personality.

The questionnaire of the Big Five Factors is one of the most widely used personality assessment in the world. In addition, the evidences indicate that Big Five is fairly stable over time (Costa \& McCare, 1988; Digman, 1989). Moreover, factor structure resembling the Big Five Factors was identified in numerous sets of variables (McCare \& Costa, 1985; Digman \& Inouye, 1986; Goldberg, 1981, 1990; John, 1990; Saucier \& Goldberg, 1996). In addition, the scales of Big Five personality have proven to be a useful tool in a number of applied fields. In this way, the Big Five Factors Inventory has enjoyed wide spread popularity in applied organizational context. The reliability reported in the manual is adequate with mean of .78 across the five factors (Costa \& McCare, 1992).

The idea of major dimensions include much of personality is long standing (Norman, 1963). In addition, Digman and Inouye (1986) state "the domain of personality of personality descriptors is almost completely accounted for by five robust factors" (p.116). In this way, the Big Five Factors personality questionnaire can be as a satisfactory tool to assess the relationship between personality and a number of academic variables (Chamorro er al., 2007). Despite the FFI enjoys international use, but the Big Five structure has not been accepted generally (Eysenck, 1992, 1997; McAdams, 1992; Block, 1995).

The dimensions composing the Big Five Factors (as cited in related literature by different dominant researchers such as Chamorro-Premuzie, Furnham \& Lewis, 2007; Costa \& McCare, 1992) are detailed as: a) Neuroticism represents the tendency to exhibit poor emotional adjustment, anxious, and pessimistic; b) 
Extraversion represents the tendency to be sociable and assertive, cheerful, active, upbeat, and optimistic; c) Openness to experiences (intellect) represents the tendency to imaginative, intellectually curious, imaginative, and artistically sensitive; d) Agreeableness is the tendency to be trusting, compliant, caring, gentle, compassionate, empathic, and cooperative; e) Conscientiousness represents the tendency to responsible, organized, hard-working, responsible, dependable, able to plan, organized, persistent, achievement oriented, purposeful, strong-willed, and determined.

The NEO-FFI is a sixty-item version of $S$ form of the NEO-PI-R that is applied to measure the five domains of personality. It is consist of five 12-item scales. Each of these sixty items includes five options. The NEO-FFI is self-scoring, and paper and pencil survey. It is 5-point scale range from "Strongly Disagree" to "Strongly Agree".

\section{Sample of the pilot study}

The sample for the pilot study, as "A small-scale replica and a rehearsal of the main study" (Riazi, 1999), was selected so as it represents the entire sample for the participants whom asked to participate in the main study. Since the sample size in the pilot study ranges from 20 to bigger of 65 (Hinkin, 1998), thirty nine female students were asked to participate in the pilot study. In this pilot study, the percent of participants from each branch is approximately equal to the others. They were told about the importance of the results of the pilot study.

\section{Reliability of the instruments}

Since Cronbach's alpha is one of the standard ways of expressing a test's reliability (Foster, 1998); and its coefficient is commonly used to describe the reliability factors of multi-point formatted questionnaires or scales; the reliability of our experimental measures were assessed by calculating Cronbach's alpha over the items of the three instruments across all the participants in the current study which were found. 72 for Adapted Inventory for Compensation Category of English Language Learning Strategies 0.82 for NEO-FFI, and 0.80 for TOEFL. The reliability coefficient indicated the degree to which the results on a scale can be considered internally consistent or reliable (Nunnally \& Bernstein, 1994; De Vellis, 2003; Moemeni, 2007; Ghiasvand, 2008) such finding of reliabilities for the three instruments confirmed the finding of reliabilities in the pilot study.

\section{Data collection procedures in the main study}

The data for the study described in this study was collected between September 2010 and November 2010 in Iran, at the Islamic Azad University Branches of three cities that are named Abadan, Dezful, and MasjedSolyman.

All of the instruments were administrated during the class time and based on the availability of the participants of third grade (year) at three stages. The researcher, himself, administrated all the instruments. All the participants participated in the main study, were explained the goals of the current study by the researcher. Also for each stage of administration, the researcher explained the instructions for answering the test and questionnaires before each of the instruments was administrated. All the explanation of the materials was performed by Persian language (which is the mother tongue of the participants).

Stage one: At this stage, the participants were asked to answer TOEFL test. Approximately 80 minutes were taken to answer the test. Such duration of time is as the duration of time was calculated in the pilot study (The first week).

Stage two: At the second stage, the respondents were asked to fill the Adapted Inventory for Compensation Category of English Language Learning Strategies. The respondents were asked to respond to the questions within 5-10 minutes. The time that assigned for participants was determined according to the results obtained from the pilot study. Along the Adapted Inventory for Compensation Category of English Language Learning Strategies, Background Questionnaire was administrated (The second week).

Stage three: At this Stage, the NEO-FFI was administrated. The time that assigned for the participants in order to complete the NEO-FFI was determined according to the results obtained from the pilot study. 1015 minutes were enough to complete the NEO-FFI (The third week).

\section{Data analysis}

After data collection, the data was entered onto databases (Excel and SPSS) to enable data analysis to be carried out.

The First procedure of data analysis includes Pearson Correlation that used to identify the strength and direction of the relationship between variables. As known to the researchers in the field, correlation does not imply causality, but it does provide a picture of relationships. The important point, the classification of strength of correlation is not well accepted among different researchers, and there are different classifications such as the classification suggested by (Cohen 1988; Ghianvand, 2008; Delavar, 2010). In the current study, the classification that was suggested by Cohen (1988) was chosen as criterion to interpret and discuss about the strength of the correlation (Table 1).

Table1. The classification was suggested by Cohen (1988)

\begin{tabular}{|c|c|}
\hline Level of Strength & Amount of the Strength \\
\hline Low & $r=.10$ to .29 \\
\hline Medium & $r=.30$ to .49 \\
\hline Strong & $r=.50$ to 1 \\
\hline
\end{tabular}

The second procedure of data analysis includes Analysis of Variance (ANOVA) that is an analytic tool. In non-experimental research, ANOVA does not show the same meaning as experimental research. In non- 
experimental research, ANOVA does not mean causality between the independent variables and the dependent variables when there is a significant relationship. In this way, the use of ANOVA in non-experimental research is criticized if the goal is finding casual relationships (Johnson, 2001). Moreover, the use of ANOVA in nonexperimental is perfectly acceptable when the goal is not causality according to top statisticians (Johenson, 2001). In addition, ANOVA has been frequently used for many years in non-experimental research (Johnson, 2001).

In this way, correlation is used to find the degree and direction of the relationship between variables, and ANOVA test the significance of the relationship.

The third procedure of data analysis includes Multiple Regression Analysis. As Newton and Rudestam (1999), point out it is used to find the relationship between multiple distributed independent variables and a single dependent variable. In such way, the researcher used multiple regressions to identify among all of the five independent variables as the best predictors of the overall use of ELLSs. In this procedure, stepwise method was used; and the interpretation of the stepwise method of multiple regressions was based on the samples of (Pallant, 2007; Ghisvand, 2008; Kalantari, 2008).

\section{Results, discussion, and conclusion}

In the entire sample, the strategies in the Compensation category were categorized as Medium frequently used strategies, with a mean of $3.2(\mathrm{SD}=.63)$ (based on the Oxford' key, 1990).

The means were calculated in order to determine the mean of the each of five traits of personality among the total group of the respondents $(\mathrm{N}=213)$ (Table 2).

Table 2. Means and standard deviations (SD) of the five traits of personality in the current study

\begin{tabular}{|l|c|c|c|}
\hline Personality Trait & $\mathrm{N}$ & Mean & SD \\
\hline Neuroticism & 213 & 23.0 & 8.3 \\
\hline Extraversion & 213 & 27.4 & 5.5 \\
\hline Openness to Experiences & 213 & 27.9 & 4.7 \\
\hline Agreeableness & 213 & 32.4 & 5.4 \\
\hline Conscientiousness & 213 & 34.7 & 6.3 \\
\hline \multicolumn{2}{|r}{ Table 2 }
\end{tabular}

Conscientiousness trait (Mean=34.7, SD $=6.3$ ) was more than each of the means of the other four traits, and the mean of the Neuroticism trait (Mean=23.0, $S D=8.3$ ) was less than each of the means of the other four traits.

The Pearson Correlation was performed to examine whether there is a relationship between the overall Compensation strategy use and the five traits of personality (Table 3).

According to Table 3, the students' overall Compensation strategy use was significant positively correlated with the Openness to Experiences trait, and Conscientiousness trait at the $p<.01$ level (2-tailed), and the Agreeableness trait at the $p<.05$ level (2-tailed). The levels of correlation were found low for the openness to Experiences trait, for the Conscientiousness trait, and for

\section{Vol. 5 No. 6 (June 2012) ISSN: 0974-6846}

the Agreeableness trait. For the Extraversion trait, and the Neuroticism trait, the correlation was non-significant. In Table 3, in the case of the significant correlations, we found only type of significant positive correlation, and the level of correlation was found to be low. Moreover, except the case of the Extraversion trait, and the Neuroticism trait, all positive correlations were significant at the $p<.01$ or $p<.05$ levels (2-tailed). There was no significant negative correlation in the table $(P>.05)$.

According to Table 3 , the students' overall Compensation strategy use was not significant correlated with the Extraversion trait $(p>.05)$. In such way, Table 3 indicated that there was not a meaningful significant relationship between the overall Compensation strategy use and the Extraversion trait.

Table 3 indicated that based on increasing of the Openness to Experiences trait level of the students, higher average of Compensation Strategies would be used, and based on decreasing of the Openness to Experiences trait level, lower average of Compensation Strategies would be used. In such way, Table 3 showed that there was a meaningful significant positive relationship between the overall Compensation strategy use and the Openness to Experiences trait $(r=.190$, $\mathrm{p}<.01$ ). The positive relationship implies that the students with higher level of Openness to Experiences trait use Compensation strategies more.

Table 3 indicated that based on increasing of the Agreeableness trait level of the students, higher average of Compensation Strategies would be used, and based on decreasing of the Agreeableness trait level, lower average of Compensation Strategies would be used. In such way, Table 3 showed that there was a meaningful significant positive relationship between the overall Compensation strategy use and the Agreeableness trait $(r=.141, p<.05)$. The positive relationship implies that the more Agreeable students use Compensation strategies more.

Table 3 indicated that based on increasing of the Conscientiousness trait level of the students, higher average of Compensation Strategies would be used, and based on decreasing of the Conscientiousness trait level, lower average of Compensation Strategies would be used. In such way, Table 3 showed that there was a meaningful significant positive relationship between the overall Compensation strategy use and the Conscientiousness trait $(r=.190, p<.01)$. The positive relationship implies that the more Conscious students use Compensation strategies more.

According to Table 3 , the students' overall Compensation strategy use was not significantly correlated with the Neuroticism trait ( $p>.05)$. In such way, Table 3 indicates that there was no significant meaningful relationship between the overall Compensation strategy use and the Neuroticism trait. 
Table 3. The summary of correlations among the overall compensation strategy use and the five traits of personality

\begin{tabular}{|c|c|c|c|c|c|c|}
\hline \multicolumn{2}{|c|}{} & Extraversion & $\begin{array}{c}\text { Openness } \\
\text { to } \\
\text { Experiences }\end{array}$ & Agreeableness & Conscientiousness & Neuroticism \\
\hline \multirow{2}{*}{$\begin{array}{c}\text { Compensation } \\
\text { Strategies }\end{array}$} & $\begin{array}{c}\text { Pearson } \\
\text { Correlation }\end{array}$ & .042 & $.190^{* *}$ & $.141^{*}$ & $.190^{* *}$ & -.125 \\
\cline { 2 - 7 } & $\begin{array}{c}\text { Sig. } \\
(2-t a i l e d)\end{array}$ & .538 & .005 & .040 & .005 & .068 \\
\cline { 2 - 7 } & $\mathrm{N}$ & 213 & 213 & 213 & 213 & 213 \\
\hline
\end{tabular}

**. Correlation is significant at the 0.01 level (2-tailed) *. Correlation is significant at the 0.05 level (2-tailed)

Table 4. The model summary of the equation

\begin{tabular}{|c|c|c|c|c|c|}
\hline Model & Variables Entered & $\mathrm{R}$ & $\mathrm{R}$ Square & Adjusted R Square & Std. Error of the Estimate \\
\hline 1 & Conscientiousness & $.190^{\mathrm{a}}$ & .036 & .032 & .62557 \\
\hline 2 & Openness to Experiences & $.252^{\mathrm{b}}$ & .064 & .055 & .61805 \\
\hline
\end{tabular}

Stepwise (criteria: probability-of-F-to-enter $<=.050$, probability-of-F-to-remove $>=.100$ ). Dependent variable: compensation strategies a. Predictors: (Constant), conscientiousness b. Predictors: (Constant), conscientiousness, openness to experiences

The Multiple Regression Analysis, for all the five traits of personality (as independent variables) and the overall use of Compensation Strategies (as a dependent variable) were analyzed through the stepwise method. Out of the five traits of personality, only two variables entered the equation (Table 4).

According to Table 4, regression analysis has run up to two steps. In the first step, the Conscientiousness trait entered the equation that the Adjusted R-Square became .032. In the second step, when the Openness to Experiences trait entered the equation, the Adjusted RSquare increased up to .055. In other words, based on the Adjusted R-Square, the emerged model for the two independent variables with the Adjusted R-Square of .055 , accounted for explaining about $5.5 \%$ of the variance of the students' overall Compensation strategy use.

Further, Table 5 (regressional ANOVA) showed that the effect was significant, and all the models had high $F$ values $(F=7.944, F=7.150, P<.01)$. Therefore, it could be concluded that about $5.5 \%$ of changes in the students' overall Compensation strategy use was accounted for by the Conscientiousness and the Openness to Experiences traits.

Table 5. The results of regressional $A N O V A^{c}$ of the equation

\begin{tabular}{|c|c|c|c|c|c|c|}
\hline \multicolumn{2}{|c|}{ Model } & $\begin{array}{c}\text { Sum of } \\
\text { squares }\end{array}$ & df & $\begin{array}{c}\text { Mean } \\
\text { square }\end{array}$ & $F$ & Sig. \\
\hline \multirow{2}{*}{1} & Regression & 3.109 & 1 & 3.109 & 7.944 & $.005^{\mathrm{a}}$ \\
\cline { 2 - 8 } & Residual & 82.571 & 211 & .391 & & \\
\cline { 2 - 8 } & Total & 85.680 & 212 & & & \\
\hline \multirow{2}{*}{2} & Regression & 5.462 & 2 & 2.731 & 7.150 & $.001^{\mathrm{b}}$ \\
\cline { 2 - 8 } & Residual & 80.218 & 210 & .382 & & \\
\cline { 2 - 8 } & Total & 85.680 & 212 & & & \\
\hline
\end{tabular}

a. Predictors: (Constant), Conscientious, $b$. Predictors:

(Constant), Conscientiousness, openness to experiences

c. Dependent Variable: Compensation Strategies
As hinted, Table 5 indicated that the effect of the Conscientiousness and the Openness to Experiences traits was significant at the $p<.01$ level. Remaining the three traits of personality did not enter the regression equation because of level of their errors were greater than 0.05 , and they had very weak effect in the prediction of the overall compensation strategy use. In such way, rest of the contribution for the overall Compensation strategy use was unaccounted.

According to Table 6, although the amount of B for the Openness to Experiences was greater than the amount of $\mathrm{B}$ for the Conscientiousness trait, the Conscientiousness trait has greater effect on the amount change of the overall compensation strategy use. The obtained Beta for the Conscientiousness trait showed that for each of one unit of value of change in the Standard Deviation, the amount of change 0.168 occurred in the Standard Deviation of the overall compensation strategy use. However, the obtained Beta for the openness to experiences trait showed that for each of one unit of value of change in its Standard Deviation, the amount of change 0.167 occurred in the Standard Deviation of the overall Compensation strategy use. All the predicted models and constants, the $t$ values ranged from 2.482 to 10.469 , which were all found to be significant, and significance levels ranged from 0.014 to 0.000 level.

Table 7 showed the excluded variables in this equation. The excluded variables at the first step were Extraversion, Openness to Experiences, Agreeableness, and Neuroticism. At the second step, the excluded variables were Extraversion, Agreeableness, and Neuroticism.

In summary, one can conclude that the traits like the Conscientiousness trait, and the Openness to

Experiences trait best predicted the overall use of Compensation Strategies of the students

Limitations of the current Study 
Indian Journal of Science and Technology

Table 6. The unstanderdised coefficients ${ }^{a}, T$ tests and significances for different models predicted of the equation

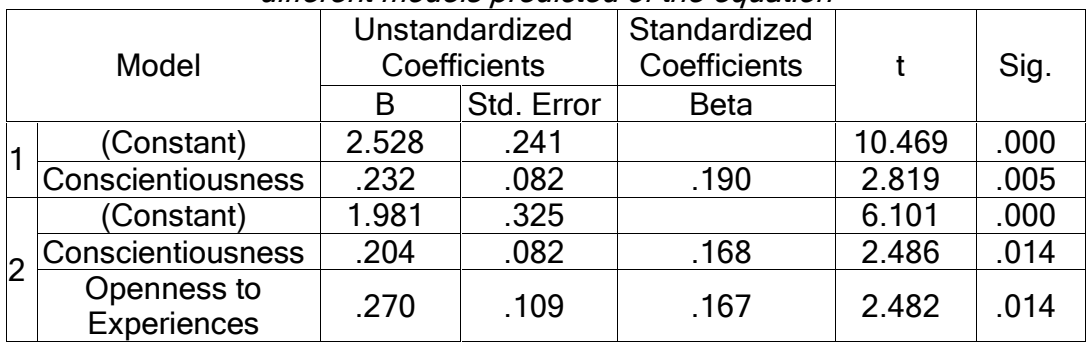

a. Dependent variable: Compensation strategies

Table 7. The Excluded variables ${ }^{c}$ of the equation

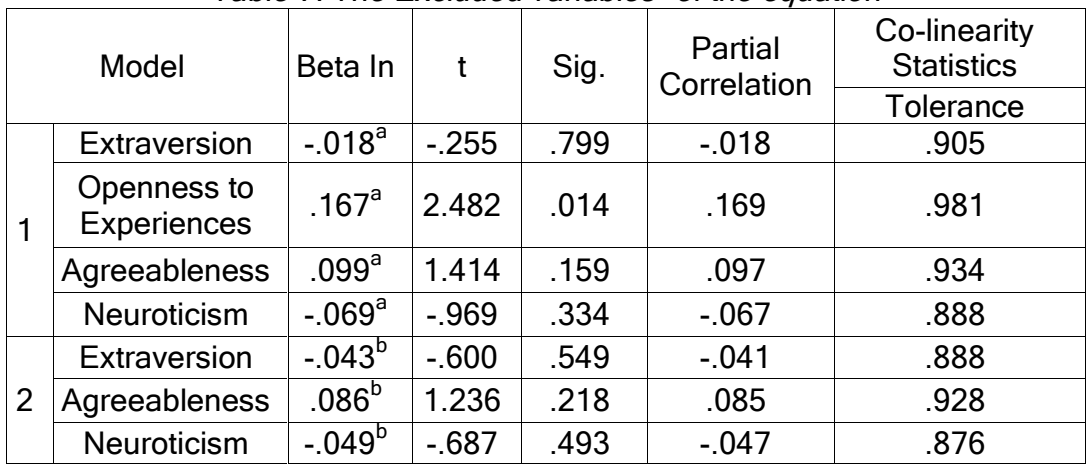

a. Predictors in the Model: (Constant), Conscientiousness, $b$. Predictors in the Model: (Constant), Conscientiousness, openness to experiences, $c$. Dependent Variable: Compensation Strategies

Generally speaking, there are some difficulties inherent in endeavor to conduct any research work regarding the learners of second/foreign language. Similarly, the present study due to using Ex Post facto type of research has certain limitations that must be taken in mind while the interpretation of the results. Moreover, since all the education quasi-research deals with living human beings occur out of laboratory conditions have limitations (Gall et al., 2003).

\section{References}

1. Block J (1995) A contrarian view of the five-factor approach to personality description. Psychol. Bulletin. 117, 187-215.

2. Brown HD (2001) Principles of language learning and teaching. Englewood Cliffs, NJ: Prentice Hall.

3. Cattel RB and Butcher H (1968) The prediction of achievement and creativity. NY: Bobbs-Merrill.

4. Chamorro-Premuzie T, Furnham A and Lewis M (2007) Personality and approaches to learning predict preference for different teaching method. Learning \& Individual Differences. 17, 241-250.

5. Cohen J (1988) Statistical power analysis for the behavioral sciences $\left(2^{\text {nd }}\right.$ ed). Hillsdale, $\mathrm{NJ}$ : Lawrence Erlbaum Associates.

6. Cook V (2008) Second language learning and language teaching ( $4^{\text {th }}$ ed.). London: Edward Arnold.

7. Costa PT and McCare RR (1988) Personality in adulthood: A six-year longitudinal study of selfreports and spouse ratings on the NEO personality Press.

Vol. 5 No. $6 \quad$ (June 2012) ISSN: 0974-6846

inventory. J. Personality \& Social Psychol. 54(4), 853-863.

8. Costa PT and McCare RR (1992) Professional Manual for the NEO-PI-R and NEO-FFI. Odessa, FL: Psychol. Assessment Res.

9. De Vellis RF (2003) Scale development: Theory and application $\left(2^{\text {nd }}\right.$ ed.). Thousand Oaks, California: Sage.

10.Delavar A (2010) Theoretical and experimental principle of research in human sciences. Tehran. Roshd Publi.

11.Digman JM and Inouye J (1986) Further specification of the five robust factors of personality. J. Personality \& Social Psychol. 50,116-123.

12.Digman JM (1989) Five robust traits dimensions: Development, stability, and utility. J. Personality. 57(1), 195-214.

13. Ehrman ME and Dornyei Z (1998) Interpersonal dynamics in second language education. Visible \& invisible classroom. Thousand Oaks, Calif: Sage Publications.

14. Ellis R (1985) Understanding second language acquisition. Oxford: Oxford Univ. Press.

15.Ellis R (1994) The study of second language acquisition. Oxford: Oxford Univ.

16. Eysenck HJ (1967) The biological basis of personality. NY: Springfield.

17. Eysenck HJ (1992) Four ways five factors are not basic. Personality \& Individual Differences. 13, 667673.

18. Eysenck HJ (1997) Personality and exponential psychology: The unification of Psychology and the possibility of a paradigm. J. Personality \& Soc. Psychol. 73, 1224-1237.

19. Foster JJ (1998) Data analysis using SPSS for window: A beginner's guide. Thousand, Oaks, California: Sage Publi.

20. Gall MD Gall JP and Borg WR (2003) Educational research: An Introduction (7 ed.). Boston: Allyn \& Bacon.

21. Ghiasvand A (2008) Application of statistics and SPSS in data analysis. Tehran: Lovieh Publi.

22. Goldberg LR (1981). Language and individual differences: The search for universals in personality lexicons. In L. Wheeler (Ed.). Rev. Personality \& Soc. Psychol. Beverrly Hills, CA: Sage. 2; 141-165.

23. Goldberg LR (1990) An alternative description of personality: The big five factor structure. J. Personality \& Soc. Psychol. 59, 1216-1229.

24. Golkar M and Yamini M (2007) Vocabulary, proficiency and reading comprehension. The Reading Matrix. 7(3), 88-112. 
25. Hampson SE and Colman AE (1995) Individual differences and personality. NY: Longman.

26. Hinkin TR (1998) A brief tutorial on the development of measures for use in survey questionnaires. Organizational Res. Methods. 1(1), 104-121.

27. Horwitz EK (1988) The beliefs about language learning of beginning university foreign language students. Modern Language J.. 72(13), 283-294.

28. Horwitz EK (1999) Cultural and situational influences on language learners' beliefs about language learning: a review of BALLI studies. System, 27, 557576.

29. Hsiao TY and Oxford RL (2002) Comparing theories of language learning strategies: A confirmatory factor analysis. Modern Language J. 86(3), 368-383.

30. John OP (1990) The big five factor taxonomy: dimensions of personality in the nature language and in the questionnaire. In L.A. Pervin (Ed.), Handbook of Personality: Theory \& Res. NY: Guliford Press. pp: 66-100.

31. Johnson B (2001) Toward a new classification of nonexperimental quantitative research. Edu. Res. 30(2), 3-13.

32. Kalantari K (2008) Data processing and analysis in socio-economic research. Tehran: Farhang Saba Publisher.

33. Larsen-Freeman D and Long MH (1991) An introduction to second language acquisition research. NY: Longman.

34. Marttinen M (2008) Vocabulary learning strategies used by upper secondary school students studying English as a second language. (Online) M.A. Dissertation. Retrieved fromMarch20,2010, from https://jyx.jyu.fi/dspace/bitstream/handle/123456789/ 18447/URN_NBN_fi_jyu200803261288.pdf?sequenc $\mathrm{e}=1$

35. McAdams DP (1992) The five-factor model in Personality: A critical appraisal. J. Personality. 60, 329-361.

36. McCare RR and Costa PT (1985) Updating Norman's adequate taxonomy: Intelligence and personality dimensions in natural language and in questionnaires. J. Personality \& Psychol. 49, 710721.

37. Moemeni M (2007) Statistical analysis with SPSS. Tehran: Ketab neo Publi.

38. Newton RR and Rudestam KE (1999) Your statistical consultant: Answers to your data analysis questions. California: Sage Publ, Inc.

39. Norman WT (1963) Toward an adequate taxonomy of personality attributes: replicated factor structure in per nomination personality ratings. J. Abnormal \& Soc. Psychol. 66, 574-583.

40. Nunnally JC and Bernstein IH (1994) Psychometric theory $\left(3^{\text {rd }}\right.$ ed. $)$. NY: McGraw-Hill.

41. Oxford RL (1990) Language learning strategies: What every teacher should know. Boston: Heinle \& Heinle.
42. Oxford RL (1992) Instructional implications of gender differences in second/foreign language learning styles and strategies. Appli. Language Learning. 4(1\& 2), 65-94.

43. Oxford RL (1993) Individual differences among your ESL students: Why a single method can't work. J. English Studies. 7, 27-42.

44. Oxford RL (1994) Language learning strategies: An update. (Online) Online resources: Digest. Retrieved March08, 2011, from http://www.cal.org/resources/digest/oxford01.html.

45. Oxford RL (1996) Employing a questionnaire to assess the use of language learning strategies. Appl. Language Learning. 7(1\& 2), 25-45.

46. Oxford RL and Burry-Stock J (1995) Assessing the use of language learning strategies worldwide with the ESL/EFL version of the Strategy Inventory for Language Learning (SILL). System. 23(1), 1-23.

47. Oxford RL and Cohen A (1992) Language learning strategies: crucial issues of concept and classification. Appl. Language Learning. 3 (1\& 2), 135.

48. Oxford RL and Crookball D (1989) Research on language learning strategies: methods, findings, and instructional issues. Modern Language J. 73(4), 404419.

49. Oxford RL and Ehrman M (1995) Adult's language learning strategies in an intensive foreign language program in the United States. System. 23(3), 359386.

50. Oxford RL and Nyikos M (1989) Variables affecting choice of language learning strategies by university students. Modern Language J. 73(3), 291-300.

51. Pallant $J$ (2007) $\left(3^{\text {rd }}\right.$ ed). SPSS survival manual: $A$ step by step guide to data analysis using SPSS for windows. New South Wales, Australia: Allen \& Unmin.

52. Perera M and Eysenck SBG (1984) A cross-cultural study of personality: Sri Lanka and England. J. Cross Cultural Psychol. 15(3), 353-371.

53. Riazi AM (1999) A dictionary of research methods: Quantitative and qualitative. Tehran: Rahnama Publ. pp.198.

54. Saklofske DH and Eysenck SBG (1998) Individual differences in children and adolescents (Eds.). New Brunswick NJ: Transaction Publishers.

55. Saucier G and Goldberg LR (1996). Evidence for the Big Five in analyses of familiar English personality adjectives. Eur. J. Personality. 7, 1-17.

56. Skehan $P$ (1989) Individual differences in secondlanguage learning. London: Edward Arnold.

57. Toyoda E (1998) Teaching kanji by focusing on learners' developing of graphemic awareness. Australian Rev. Appl. Linguistics. 21(15), 155-168. 